Check for updates

The BMJ

Cite this as: $B M J 2021 ; 372: n 13$ http://dx.doi.org/10.1136/bmj.n13 Published: 04 January 2021

\title{
Covid-19: Health secretary vows to reduce bureaucracy faced by vaccination volunteers
}

Abi Rimmer

Doctors volunteering to give the covid-19 vaccine should not have to undertake unnecessary training, such as on preventing terrorism, the health secretary has said.

Retired doctors who have volunteered to help with the vaccine roll out through NHS Professionals have been asked to complete 18 training modules which include preventing radicalisation and fire safety. One retired GP said on Twitter that she had given up trying to sign up to volunteer after spending seven hours reading about things she already knew. "I just wanted to help," she said.

Speaking on the Today programme on 4 January, Matt Hancock said that he would remove some of the requirements, including preventing radicalisation training. "At the moment the NHS has all the people that it needs to deliver the vaccine on the current schedule, but is also hiring people, including some retired clinicians, in order to have yet more when the delivery ramps up in the months ahead," he said. "Some of the training that has been put in place I don't think is necessary."

Hancock said he would go through the training requirements for vaccinators "line by line" to check that only what was necessary was included "because training for this role is very important-this is an important, sensitive job-but is not gold plated."

The news comes after Prime Minister Boris Johnson was asked on The Andrew Marr Show on 3 January whether he thought it was reasonable that retired doctors hoping to help give the vaccine were being asked to fill out forms on de-radicalisation measures and fire drills. " "I don't," Johnson said, “It's absurd and I know the health secretary has taken steps to get rid of that pointless bureaucracy."

Martin Marshall, chair of the Royal College of General Practitioners, said that there was an "army" of retired medics waiting to help with the vaccine roll out. "We need to allow them to do so and keep bureaucratic barriers to the bare minimum.

"Requiring people to submit more than 20 pieces of documentation, some of which have low relevance to the task they will be doing, and which some retired medics and returners to the profession won't even have, is a deterrent to them getting involved at a time when we need all hands on deck."

Elsewhere, retired doctors have complained that they have tried to volunteer with the vaccine roll out but have not had a response from NHS Professionals or other local organisations.

Melanie Jones, a retired anaesthetist in Wales, said that she contacted the Wales covid-19 hub in April 2020 and informed them of the work she was willing to do. ${ }^{3}$ She has, however, still not been contacted or asked to undertake any work for the NHS. "I could be a vaccinator. I'm not looking to oversee a team or manage a clinical service. I'm a retired person who would be quite happy to spend half a day, three days a week, helping a vaccine team," Jones said.

She added, "I'm sad that there are people who could help to ease the pressure on our colleagues and yet there seems to be a disconnect between people who want to help and people who are asking for help-somehow there is a barrier in the middle."

A Department of Health and Social Care spokesperson said, "There are no delays in covid-19 vaccination caused by accrediting volunteers or returners. We had an outstanding response from former healthcare professionals to support the NHS during the pandemic and, as the health secretary said this morning, we are working with the NHS to streamline the returner programme as much as possible.”

Maureen Richmond. 1 January 2021. https://twitter.com/MaureenRichmon4/status/1345060826965827586.

2 The Andrew Marr Show. 3 January 2021. www.bbc.co.uk/iplayer/episode/m000r09z/the-andrew-marr-show-03012021.

3 Melaine Jones. 30 December 2020. https://twitter.com/medicsupport/status/1344238940597923841. 